\title{
Transurethral Resection of the Ejaculatory Ducts in Treatment of Male Infertility: The Surgical Technique and the Role of Transrectal Ultrasound
}

Marcelo Esteves Chaves Campos, MD, MSc

Department of Urology, Federal University of Minas Gerais, Belo Horizonte, Brazil. E-mail: camposmec@yahoo.com.br

Rodrigo Lolli Almeida Salles, MD

Department of Urology, Federal University of Minas Gerais, Belo Horizonte, Brazil.

Augusto Barbosa Reis, MD, PhD

Department of Urology, Federal University of Minas Gerais, Belo Horizonte, Brazil.

Reginaldo Martello, MD, PhD

Department of Urology, Federal University of Minas Gerais, Belo Horizonte, Brazil.

Thiago Pardini Furtado, MD

Department of Urology, Federal University of Minas Gerais, Belo Horizonte, Brazil.

Viacheslav Iremashvili, MD, PhD

Department of Urology, United Hospital Center, Bridgeport, West Virginia.

(c) Mary Ann Liebert, Inc. DOI: 10.1089/vid.2019.0083
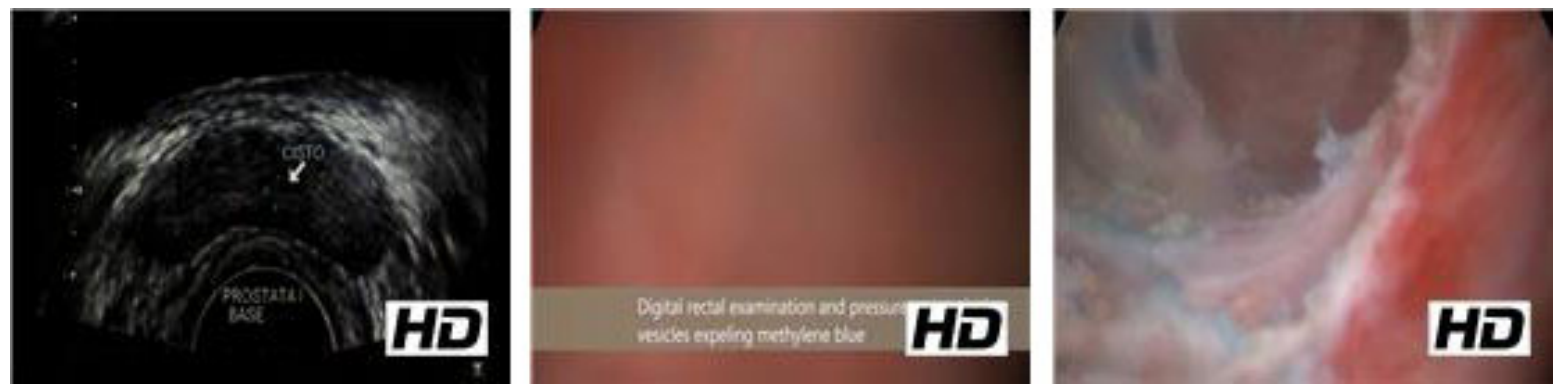

\section{Abstract}

Introduction: Prostatic cysts are rare lesions that may cause compression of the ejaculatory ducts resulting in azoospermia. ${ }^{1}$ Transrectal ultrasound (TRUS) may identify midline cysts that may be acquired or congenital. ${ }^{2,3}$ Transurethral resection of the ejaculatory ducts (TURED) may be an effective treatment for obstructive azoospermic infertile men. ${ }^{4,5}$ The aim of this study was to describe our experience with TRUS and TURED as diagnostic and therapeutic tools in the management of ejaculatory duct obstruction caused by prostatic cysts and causing male infertility.

Methods: We report a clinical case of male infertility to demonstrate the role of TRUS in performing effective TURED for obstructive azoospermia caused by midline cyst. Patient presented with azoospermia, low ejaculate volume $(0.2 \mathrm{~mL})$, and low ejaculate $\mathrm{pH}(6.4)$. Vasal aplasia and ejaculatory disorders were excluded by physical examination and analyzing postejaculatory urine. TRUS revealed a cystic lesion located in the middle of the prostate. During the procedure we injected methylene blue into each seminal vesicle under TRUS guidance. TURED near the verumontanum in the midline was then performed using only cutting current to minimize damage to the ejaculatory ducts that could cause restenosis. The level of resection was guided by synchronous TRUS to verify location 
of the cyst and avoid inadvertent injury to the rectum. At the correct level of resection, methylene blue was seen flowing from the opened ducts. Patient required urethral catheter for 24 hours postoperatively. After the TURED procedure, ejaculation was resumed after 2 weeks, when a formal semen analysis was carried out and then repeated every month until the seminal parameters stabilized.

Results: Even though the seminal volume improvement $(10.1 \mathrm{~mL})$ was seen in the first month of follow-up, it took about 6 months for semen quality parameters $(230.6$ million count, $51 \%$ motility and $43 \%$ morphology) to reach their peak values. Watery ejaculate occurred and spontaneous pregnancy was achieved.

Conclusions: TRUS is an essential instrument that allows to confirm the diagnosis of prostatic cysts and guide TURED. In our experience this combination was effective in reestablishing free passage of semen with potential recovery of fertility.

Patient Consent Statement: Authors have received and archived patient consent for video recording/ publication in advance of video recording of procedure.

Music: Airport Lounge-Disco Ultralounge by Kevin MacLeod is licensed under a Creative Commons Attribution license (https://creativecommons.org/licenses/by/4.0/).

Source: http://incompetech.com/music/royalty-free/index.html?isrc=USUAN1100806

Artist: http://incompetech.com/

The authors declare that no competing financial interests exist.

Runtime of video: 5 mins 43 secs

Keywords: prostatic cysts, ejaculatory ducts, azoospermia, ultrasound, male infertility, transurethral resection

\section{Cite this video}

Campos MEC, Salles RLA, Reis AB, Martello R, Furtado TP, Iremashvili V, Transurethral resection of the ejaculatory ducts in treatment of male infertility: the surgical technique and the role of transrectal ultrasound, Videourology. 2020, DOI: 10.1089/vid.2019.0083.

\section{References}

1. Nayyar R, Dogra PN. Anteriorly placed midline intraprostatic cyst. J Endourol 2009;23:595-597.

2. Saito $S$. Transrectal ultrasound-guided puncture, drainage, and minocycline hydrochloride sclerotherapy for the symptomatic prostatic cyst. J Endourol 2002;16:693-695.

3. Manohar T, Ganpule A, Desai M. Transrectal ultrasound- and fluoroscopic-assisted transurethral incision of ejaculatory ducts: A problem-solving approach to nonmalignant hematospermia due to ejaculatory duct obstruction. J Endourol 2008;22:1531-1535.

4. Modgil V, Rai S, Ralph DJ, Muneer A. An update on the diagnosis and management of ejaculatory duct obstruction. Nat Rev Urol 2016;13:13-20.

5. Avellino GJ, Lipshultz LI, Sigman M, Hwang K. Transurethral resection of the ejaculatory ducts: Etiology of obstruction and surgical treatment options. Fertil Steril 2019;111:427-443.

Original Publication Date: 2020 